facilitate the investigation of the embryo-sac. In many species it is impossible to correlate its growth with external features of the ovule or ovary, and in consequence the detailed examination of any particular stage of development often at present involves much fruitless searching. If techniques for the culture of gametophytes alone could be worked out for only one or two species, it would none the less be a great advance to be able to view at last the cytology of the embryo-sac dynamically, and perhaps even discover by experimental means the factors causing its nuclei to differ so markedly from each other in behaviour.

Not considered anywhere at length in this volume, but haunting its pages, is the fact that cultural methods have shown elsewhere that the phenomenon of embryogenesis is not necessarily confined to the reproductive cycle. It can be fairly inferred from the recent spectacular developments in the culture of single cells of higher plants that any diploid cell, in which irreversible differentiation has not proceeded too far, will, if placed in an appropriate medium, develop in an embryo-like way and produce a complete plant. The whole complex sexual apparatus is not therefore an essential prerequisite for the removal of the effects of ageing and the re-establishment of embryonic properties. The events occurring in the ovule after fertilization thus provide only a special case of embryogeny, and one incidentally that is cortainly more difficult to study in terms of physies and chemistry than those artificial systems in which, with increasing resemblance to the natural development of zygotes, single cells generate plantlets. So far as the study of the causal mechanisms governing the regular patterns of embryogenesis is concerned, embryologists will probably in the immediate future turn more profitably to the culture flask than to the microtome.

The investigation of the natural reproductive system should not of course be neglected. It provides problems enough, particularly with regard to the quite violent macromolecular events which seem to occur at certain stages, to last for several decades. What is the significance of the massive extrusions from nucleoli into the nucleus, and ultimately into the cytoplasm, said to occur in both megasporocytes and embryo-sacs? Why do egg cells frequently have very large nuclei, less dense than the cytoplasm? Do egg nuclei really suffer a depletion of deoxyribonucleic acid as fertilization approaches, as several investigators have claimed? The accumulating indications of non-chromosomal deoxyribonucleic acid in somatic cells, present in both nucleus and cytoplasm (here especially in mitochondria and plastids), heighten interest in the eytochemistry of eggs. Unfortunately the contributors to Recent Advances are silent on the wider significance of these and of the many other peculiar features of the reproductive cells and tissues they describe.

If any general criticism is to be made of Recent Advances in the Embryology of Angiosperms it is that, although the food is good, there is a notable absence of spice, in the form of reasoned speculation and discussion, to make it an exciting meal. Nevertheless, coming at a time when there is growing interest in morphogenesis, the volume should be well received.

P. R. BeLI

\section{AMELIORATING THE POVERTY OF ECONOMICS}

The Economics of the Developing Countries

By H. Myint. Pp. 192. (London: Hutchinson and Co. (Publishers), Ltd., 1964.) 30s, net.

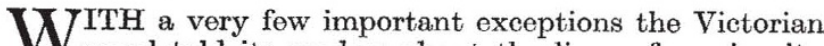
novel told its readers about the lives of a minority of Victorians, those of the wealthy and educated classes. Similarly in the first half of this century British theatre and cinema left unexplored the lives of the kind of people who make up a majority of Britons. Only recently has there been room other than at the box-office for men and women whose earnings are covered by Ministry of Labour statistics. This latter-day widening of the social vision of creative artists may partly be due to increasing democratic pressures, both political and economic, but seems more the result of the competitive spread of television.

A parallel with all this is to be found in economies. Until the 1950 's, economic literature was devoted very largely to the problem of that small proportion of mankind living in wealthy countries. Economic theory was geared to the problems of these wealthy countries and based on assumptions which fitted their characteristics. Paradoxically for a subject which defines its interest as the study of problems arising out of the basic fact of scarcity, the great majority of economists had their interests firmly located in those parts of the world where scarcity is least important and where 'over-production' emerged as a problem. Even in 1964 the Journal of the Royal Economic Society could publish a survey of the contributions made to the theory of economic growth in the past twenty-five years which did not cover the development of economically backward countries. But as in culture, so in economics. Outside pressures have recently produced a rapid shift of emphasis and interest. The competitive part played by television in our cultural parallel has been played by communism in the development of economics. The appeal of communism has come either from the economic aid offered by communist countries or from its claim to offer a short-cut to industrialization and rapidly rising economic wealth. This second, ideological, appeal has not, until very recently, taken the form of economic expertise aimed at hastening development. Even now the best schooling which eastern Europe offers to economists and administrators from developing countries draws heavily on the work of 'Western' economists whose writings are a response to the political challenge of communism.

Mr. Myint's The Economics of the Developing Countries is a critical guide to the principal theories of economic development which have come into recent prominence (his reading list of seventeen items contains nothing before 1953). He relates theory effectively to the real problem of backwardness and most succesfully avoids the generalizations which such a wide field can so easily encourage. To have done this in less than two hundred pages is a tribute to Mr. Myint's intellectual and stylistic clarity. The book is multi-purpose, serving both as a text-book for undergraduates with a basis in economics and as a way in for the non-specialist who wants to understand the problems of economic development and the belated contributions which economics is making to their solution. Natural scientists will find in it a more sophisticated treatment of population pressures than is deployed in the apocalyptic semi-popular writings on this topic, although Mr. Myint's conclusions are, if anything, more pessimistic.

The book concentrates on the theoretical aspects of economic development, and theory is construed to exclude any introduction to the techniques which an economist working in this field must use. This is unfortunate. Alongside the excellent discussion of balanced growth theory, for example, it would have been useful to have had some discussion of how feasibility studies are made, and of the techniques and statistical requirements of inter-industries analysis. This deficiency may be the price paid for trying to satisfy two markets. Certainly an introduction to techniques for economics students would have required more space than could have been spared in this book. But it is a pity that the non-specialist, who can learn much from this book, will lay it down without having been given more than a hint of how economists are beginning to make their elegant theories operational.

K. J. W. Alexander 